\title{
Utilisation of antenatal services at comprehensive health center umunya, anambra state: a retrospective study
}

Uloma Agu'*, Maurice C. Agu² and Godswill A. Nnaji

*Correspondence: ask4realuloma@Yahoo.com

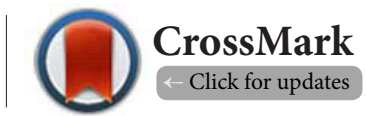

'Department of Family Medicine, Nnamdi Azikiwe University Teaching Hospital, Nnewi, Nigeria.

${ }^{2}$ College of Health Technology, Obosi, Anambra State, Nigeria.

\begin{abstract}
Background: Early antenatal booking leads to early detection and management of abnormalities resulting in a reduction in maternal morbidity and mortality rates. The study sought to determine the frequency of antenatal visits, the gestational age at booking and to audit the provision and examine the utilization of antenatal services provided at Comprehensive Health Centre, Umunya.

Methods: A retrospective, cross sectional, descriptive study carried out among women who delivered at comprehensive health center, Umunya from January 2007 to July 2014. A sample size of 323 determined by Vaughan's formula was used. Data was extracted from the patients' records and analysed using SPSS 15. Chi-square tests was used as test of significance at $\mathrm{p}<0.05$.

Results: Mean gestational age at booking was (mean $\pm \mathrm{SD}), 22.76 \pm 8.151$ weeks. Approximately, two thirds of the women $(66.3 \%)$ attended antenatal clinic $\geq 4$ times. The assessment of antenatal care services at the center showed that height and weight measurements were done in $33.7 \%$ and $65.9 \%$, respectively. Blood pressure was recorded in $99.7 \%$, while almost all the women $(95.6 \%)$ had routine iron and folic acid supplementation prescribed. Intermittent malaria prophylaxis was prescribed in $19.5 \%$ of the women. Tetanus toxoid immunization was administered in $80.5 \%$ of the women. In the examination of the utilization of the services, heamoglobin assessment was recorded in $82 \%$ of the women, urinalysis in 292 (90.4\%), HIV screening in $99.4 \%$, Syphilis test in $75.5 \%$ and Blood group test in $77.7 \%$.

Conclusion: The study demonstrates suboptimal provision of services especially with height and weight measurements and prescription of malaria intermittent preventive therapy. It also showed suboptimal utilization of laboratory services.
\end{abstract}

Keywords: Utilization of ANC services, provision of ANC services, laboratory investigation, antenatal visits

\section{Introduction}

Antenatal care is promotive health care given to pregnant women. It is the first contact for pregnant women to connect with health care delivery system. An estimated 358,000 women died from complications of pregnancy in the year 2008 and $99 \%$ of these deaths occurred in developing countries of which three fifths occurred in Sub-Saharan Africa [1]. In Nigeria, the maternal mortality ratio is as high as 800 deaths per 100,000 live births [2].

The purpose of antenatal care is to maintain the mother and baby in the best possible state of health. It is relevant for the improvement of maternal health as it enables the monitoring of the health of the mother and anticipation of any difficulties during pregnancy, labor and birth [3]. Early start of antenatal care enables the health providers to determine a woman's baseline health, makes for early detection and management of abnormalities.

The content of antenatal care commonly includes physical examination, Height, weight and blood pressure measurements, laboratory investigations and screening tests which include Voluntary Counseling and Testing and HIV screening, screening for anaemia, urinalysis, screening for syphilis, while preventive contents include giving tetanus toxoid immunizations, nutritional supplements (iron and folic acid supplements), and intermittent 
Agu et al. Family Practice Reports 2015,

preventive therapy. Several studies have linked proper antenatal care with reduced infant mortality rates $[4,5]$.

Provision of skilled care to mothers during pregnancy and delivery will reduce the rates of maternal mortality and morbidity. Women who seek care early are likely to be on nutritional supplements for a longer period thus reducing the prevalence of anaemia. These can take place when mothers present early and make frequent visits for care and when the health workers also provide adequate antenatal services. The provision of prevention of mother to child transmission of HIV and antiretroviral treatment and anti-malaria prophylaxis are also good reasons to seek early antenatal care.

The study was therefore conducted to evaluate the frequency of antenatal visits, the gestational age at booking, to audit the quality of the antenatal services provided and examine the utilization of the services at $\mathrm{CHC}$ Umunya. Understanding the pattern of usage of antenatal care at Umunya will help health workers meet the needs of these patients.

\section{Materials and methods}

Umunya is an outstation of the Nnamdi Azikiwe University Teaching Hospital, Nnewi. It provides care to the rural community of Umunya and the environs.

\section{Study design and population}

A retrospective, cross sectional, descriptive study was conducted using antenatal and delivery records of women who delivered at comprehensive health center Umunya from January 2007-July 2014.

\section{Sample size determination}

A minimal sample size of 323 was used for the study. The determination of sample size was calculated using the Vaughan's formula as follows [6]:

$\mathrm{N}=\mathrm{PQ} /(\mathrm{E} / 1.96)^{2}$

Where $P$ is the maximum expected attendance rate of pregnant women to antenatal cclinics.

$Q$ is $100-P$

$E$ is the margin of sample error tolerated in percentage $(5 \%$ being the maximum accepted value).

Using a attendance rate of an approximated average of $70 \%$ of pregnant women using antenatal care services in Nigeria (a summation of a Nigerian figure of $61 \%$ [7] and a Ibadan, Nigeria figure of $76.8 \%$ [8] ) a sample population of 323 was used.

\section{Sampling procedure}

Consecutive and complete records of the patients who attended antenatal clinics during the period of the study were retrieved and data collected from each until the required sample size was obtained.

\section{Instrument}

The instrument for data collection was a questionnaire that was designed to extract information about the participants' demographic data, their gestational age at booking, and the antenatal care services that were prescribed and those utilized that were recorded. The copies of the questionnaire were given to three experts in the department of family medicine who examined the content of the questionnaire items, their level of clarity, appropriateness of the language used and the ability of the instrument to elicit accurate information in relation to the purpose of the study.

\section{Study protocol}

During the first antenatal visits, full and relevant histories are taken and documented. Physical examination included inspection and palpation of the pregnant woman, measurement of the symphysio-fundal height (SFH) and auscultation performed after 26 weeks of gestation.

The date of the first day of the last menstrual period (LMP) was used to determine the gestational age (GA) and expected date of delivery (EDD). Palpation of the abdomen and SFH measurements was used to support the EDD. SFH measurement was used if the LMP was unknown. Obstetric ultrasound was used to confirm the expected dates of delivery if the woman was unsure of her dates or if there was any other need.

Blood pressure was measured and urine dipstick test was done during each visit for the screening of protein and glucose in the urine. Voluntary counseling for HIV were offered to all pregnant mothers, but HIV testing was done voluntarily. Those who tested positive were included in the PMTCT program. Screening test for HIV was free at this centre.

Blood samples were taken to assess haemoglobin levels using a haemoglobinometer during the antenatal visits. Tests for blood group, Rhesus factor and screening for syphilis using a rapid plasma reagin test were ordered. These tests were done after voluntary presentation of the woman to the laboratory and after payment for the services.

After consultation, sufficient ferrous sulphate and folic acid tablets were prescribed for supplementation, which will last till the next appointment. Other drugs and malaria preventive therapy were also prescribed. Tetanus toxoid immunization was also given to prevent neonatal tetanus, $0.5 \mathrm{ml}$ of the toxoid was administered intramuscularly. This was given at the first visit if this visit was in the second trimester or later in the second trimester if the first visit was earlier. This was followed by a second dose after 4 weeks.

\section{Data analysis}

Data was analyzed using SPSS 15. Descriptive statistics was used to display results, while Chi-square test was used for test of significance at $p \leq 0.05$.

\section{Ethical precepts}

The records were handled with utmost confidentiality and patients records were returned to the file racks immediately after relevant information was extracted from files. The information was treated anonymously revealing no identities. 
Agu et al. Family Practice Reports 2015,

\section{Results}

The mean age of the study population was (Mean \pm SD) $27.34 \pm 5.178$ years, while the age range was from 16 to 40 years. Most of the women were between 26 and 30 years (Table 1). Marital status showed that most of them were married $(97.8 \%)$, while only 7 (2.2\%) were single mothers.

Most of the mothers were multiparous (61.9\%), while primigravid (27.6\%) and grand-multiparous (10.5\%) were in minority. Majority were of the lower social class. A little less than two third of the women $-64 \%$ had a source of income while $36 \%$ had no income. Out of those who had an income, $56.0 \%$ were petty traders (see Table 1 ).

Mean gestational age at booking was (Mean \pm SD) 22.76 \pm 8.151 weeks. Forty six women (14.2\%) booked at 13 weeks of gestation or less (see Table 2). More than half of the women (66.3\%) attended antenatal clinic 4 times or more (See Table 2 ).

Components of antenatal care that were prescribed or utilized are shown in Table 3. Iron/folic acid supplements were prescribed for $95.6 \%$ of the women. Malarial prophylaxis was prescribed

Table 1. Frequency of socioeconomic variables among pregnant women.

\begin{tabular}{lll}
\hline Variables & Frequency & Percent \\
\hline Age group & & \\
\hline $16-20$ & 35 & 10.8 \\
$21-25$ & 85 & 26.3 \\
$26-30$ & 124 & 38.4 \\
$31-35$ & 55 & 17.0 \\
$36-40$ & 24 & 7.4 \\
\hline Parity & & \\
\hline $\mathrm{P}^{0}$ & 89 & 27.6 \\
$\mathrm{P}^{1-4}$ & 200 & 61.9 \\
$\mathrm{P}^{5}$ and above & 34 & 10.5 \\
\hline Marital status & & \\
\hline Single & 7 & 2.2 \\
Married & 316 & 97.8 \\
\hline Occupation & & \\
\hline Civil servant & 27 & 8.4 \\
Petty trader & 116 & 35.9 \\
Artisan & 46 & 14.2 \\
Unemployed house wife & 78 & 24.1 \\
Student & 37 & 11.5 \\
Farmer & 16 & 5.0 \\
Clergy & 2 & 0.6 \\
House help & 1 & 0.3 \\
\hline Social classification & & \\
\hline Upper class & 0 & 0 \\
Middle class & 27 & 8.4 \\
Lower class & 296 & 91.6 \\
\hline Income & & \\
\hline Yes & 207 & 64 \\
No & 116 & 36 \\
Total & 323 & 100 \\
\hline & & \\
\hline & & \\
\hline & & \\
\hline & & \\
\hline & & \\
\hline
\end{tabular}

Table 2. Frequency distribution of gestational age at booking and ANC visits.

\begin{tabular}{lll}
\hline Booking gestational age & Number & Percent \\
\hline$<13$ & 46 & 14.2 \\
$14-26$ & 175 & 54.2 \\
$27-41$ & 102 & 31.6 \\
\hline Frequency of antenatal visits & & \\
\hline $1-3$ & 109 & 33.7 \\
$4-8$ & 184 & 57.0 \\
$>8$ & 30 & 9.3 \\
Total & 323 & 100 \\
\hline
\end{tabular}

Table 3. Frequency distribution of components of antenatal care services

\begin{tabular}{|c|c|c|}
\hline Variable & Number & Percent \\
\hline \multicolumn{3}{|c|}{ Prescription of iron/folic acid supplement } \\
\hline Yes & 309 & 95.6 \\
\hline No & 14 & 4.4 \\
\hline \multicolumn{3}{|l|}{ Prescription for malaria prophylaxis } \\
\hline Yes & 63 & 19.5 \\
\hline No & 260 & 80.5 \\
\hline \multicolumn{3}{|l|}{ Tetanus Toxoid vaccination } \\
\hline Yes & 260 & 80.5 \\
\hline No & 63 & 19.5 \\
\hline One dose of tetanus toxoid received & 17 & 5.3 \\
\hline Two doses of tetanus toxoid received & 240 & 74.3 \\
\hline Three doses of tetanus toxoid received & 3 & 0.92 \\
\hline \multicolumn{3}{|l|}{ Hemoglobin level test done } \\
\hline Yes & 265 & 82 \\
\hline No & 58 & 18 \\
\hline \multicolumn{3}{|l|}{ Urinalysis } \\
\hline Yes & 292 & 90.4 \\
\hline No & 31 & 9.6 \\
\hline \multicolumn{3}{|l|}{ Syphilis test } \\
\hline Yes & 244 & 75.5 \\
\hline No & 79 & 24.5 \\
\hline \multicolumn{3}{|l|}{ Blood group test } \\
\hline Yes & 251 & 77.7 \\
\hline No & 72 & 22.3 \\
\hline \multicolumn{3}{|l|}{ HIV test } \\
\hline Yes & 321 & 99.7 \\
\hline No & 2 & 0.6 \\
\hline \multicolumn{3}{|l|}{ Blood pressure check } \\
\hline Yes & 322 & 99.7 \\
\hline No & 1 & 0.3 \\
\hline \multicolumn{3}{|l|}{ Height measure } \\
\hline Yes & 109 & 33.7 \\
\hline No & 214 & 66.3 \\
\hline \multicolumn{3}{|l|}{ Weight measure } \\
\hline Yes & 213 & 65.9 \\
\hline No & 110 & 34.1 \\
\hline Total & 323 & 100 \\
\hline
\end{tabular}


Agu et al. Family Practice Reports 2015,

for $19.5 \%$, while in $80.5 \%$ of the women, the prescriptions were not written. Tetanus toxoid immunization was given to $80.5 \%$ of the women. Seventeen of the women (5.3\%) had only one dose while $240(74.3 \%)$ had two doses and $3(0.92 \%)$ had three doses.

Heamoglobin assessment was performed by $82 \%$ of the women out of which. 265 (76.8\%) had only one record of haemoglobin estimation.

Urinalysis was performed by $292(90.4 \%)$ of the women.
Most had two (24.8\%) urinalysis done followed by those who did thrice (16.4\%).

Syphilis test was recorded in $75.5 \%$ of the women, while blood group test was done in $77.7 \%$.

Voluntary counseling and testing for HIV was done in $99.4 \%$ mothers. Similarly, blood pressure measurement was taken in $99.7 \%$ of mothers, while height was measured in only $33.7 \%$ and weight in $65.9 \%$ of mothers.

Table 4 showed no significant association between age and

Table 4. Cross tabulation between age groups and frequency of haemoglobin measurements, syphilis test, blood group test, tetanus vaccination and frequency of malaria prophylaxis prescription.

\begin{tabular}{|c|c|c|c|c|c|c|c|}
\hline \multirow{2}{*}{$\begin{array}{l}\text { Variable } \\
\text { Age group }\end{array}$} & \multicolumn{6}{|c|}{ Frequency of hemoglobin assessment } & \multirow{2}{*}{$\begin{array}{l}\text { P-value } \\
0.51\end{array}$} \\
\hline & 0 & \multicolumn{2}{|l|}{1} & 2 & 3 & Total & \\
\hline $16-20$ & 9 & \multicolumn{2}{|l|}{24} & 2 & 0 & 35 & \\
\hline $21-25$ & 18 & \multicolumn{2}{|l|}{63} & 4 & 0 & 85 & \\
\hline $26-30$ & 17 & \multicolumn{2}{|l|}{99} & 7 & 1 & 124 & \\
\hline $31-35$ & 10 & \multicolumn{2}{|l|}{43} & 2 & 0 & 55 & \\
\hline $36-40$ & 4 & \multicolumn{2}{|l|}{19} & 0 & 1 & 24 & \\
\hline Total & 58 & \multicolumn{2}{|l|}{248} & 15 & 2 & 323 & \\
\hline \multirow[t]{2}{*}{ Age group } & \multicolumn{7}{|c|}{ Syphilis test } \\
\hline & \multicolumn{3}{|c|}{ Yes } & \multicolumn{2}{|l|}{ No } & Total & P-value \\
\hline $16-20$ & \multicolumn{3}{|l|}{25} & \multicolumn{2}{|l|}{10} & 35 & \\
\hline $21-25$ & \multicolumn{3}{|l|}{58} & \multicolumn{2}{|l|}{27} & 85 & \\
\hline $26-30$ & 102 & & & 22 & & 124 & \\
\hline $31-35$ & 38 & & & 17 & & 55 & 0.07 \\
\hline $36-40$ & 21 & & & 3 & & 24 & \\
\hline Total & 244 & & & 79 & & 323 & \\
\hline Age group & Blood & test & & & & & \\
\hline & Yes & & & No & & Total & P-value \\
\hline $16-20$ & 25 & & & 10 & & 35 & \\
\hline $21-25$ & 64 & & & 21 & & 85 & \\
\hline $26-30$ & 104 & & & 20 & & 124 & 0.16 \\
\hline $31-35$ & 38 & & & 17 & & 55 & 0.16 \\
\hline $36-40$ & 20 & & & 4 & & 24 & \\
\hline Total & 251 & & & 72 & & 323 & \\
\hline Age group & Malar & hylaxis pre & scription & & & & \\
\hline & Yes & & & No & & Total & P-value \\
\hline $16-20$ & 6 & & & 29 & & 35 & \\
\hline $21-25$ & 20 & & & 65 & & 85 & \\
\hline $26-30$ & 24 & & & 100 & & 124 & \\
\hline $31-35$ & 8 & & & 47 & & 55 & 0.76 \\
\hline $36-40$ & 5 & & & 19 & & 24 & \\
\hline Total & 63 & & & 260 & & 323 & \\
\hline Age group & Tetant & id vaccinat & ion & & & & \\
\hline & none & One dose & Two doses & Three doses & Total & P-value & \\
\hline $16-20$ & 10 & 4 & $21(60 \%)$ & 0 & 35 & 0.027 (Sig) & \\
\hline $21-25$ & 19 & 4 & $62(73 \%)$ & 0 & 85 & & \\
\hline $26-30$ & 21 & 4 & $99(80 \%)$ & 0 & 124 & & \\
\hline $31-35$ & 8 & 4 & $40(72 \%)$ & 3 & 55 & & \\
\hline $36-40$ & 5 & 1 & $18(75 \%)$ & 0 & 24 & & \\
\hline Total & 63 & 17 & 240 & 3 & 323 & & \\
\hline
\end{tabular}

Age was significantly associated with uptake of tetanus toxoid 
Agu et al. Family Practice Reports 2015,

the various components of healthcare services provided and utilized by the mothers. The relationship between age group and the components of antenatal care was only significant in the tetanus toxoid immunization. Women in age group 16-20 years had the least number of the minimum two vaccinations.

Table 5 showed that the association between parity and the various components of health care services provided and utilized by the mothers were not significant.

Table 6 showed that income was related significantly to the performance of the syphilis and blood group test. It was not significantly related to hemoglobin test or tetanus toxoid vaccination.

\section{Discussion}

Antenatal care is regarded as the corner stone of maternal and perinatal health care. The study found the mean number of visits for antenatal care was $4.87 \pm 2.6$ visits. This figure was similar to what was obtained by Osungbade et al [9]. More than half of the women in this study reached the four or more antenatal visits as recommended by WHO [10].
Demographic analyses of the study population showed that majority (91.6\%) of the study population were from the low socioeconomic stratum of the society [11]. Many of them were petty traders. This is probably one of the reasons for the low performance of important tests. Since many of the laboratory services attract some charges, (except HIV screen) it is probable that lack of funds would account for the poor utilization of antenatal services among this study population.

The mean booking gestational age of $22.75 \pm 8.15$ is similar to what was observed in other studies in Nigeria $[9, \mathbf{9}, \mathbf{1 3}]$. The implication of this finding is that these women started attending antenatal care after the period of embryogenesis, when the organs are developed. Teratogenic substances (herbs, drugs, etc) taken during this period could affect organogenesis. Early booking with patient education could offer patient education against the consumption of any harmful or unwholesome herb and doubtful medication.

Mere attendance at a health facility is insufficient for achieving the goals of antenatal care. The quality and utilization of

Table 5. Cross tabulation between parity and frequency of haemoglobin measurements, syphilis test, blood group test, tetanus vaccination and frequency of malaria prophylaxis prescription.

\begin{tabular}{|c|c|c|c|c|c|c|}
\hline \multirow[t]{2}{*}{ Parity } & \multicolumn{6}{|c|}{ Frequency of hemoglobin assessment } \\
\hline & None & Once & Twice & Thrice & Total & Significance \\
\hline $\mathrm{P}^{0}$ & 14 & 70 & 5 & 0 & 89 & 0.57 \\
\hline $\mathrm{P}^{1-4}$ & 35 & 153 & 10 & 2 & 200 & \\
\hline $\mathrm{P}^{5}$ and above & 9 & 25 & 0 & 0 & 34 & \\
\hline \multirow[t]{3}{*}{ Total } & 58 & 248 & 15 & 2 & 323 & \\
\hline & \multicolumn{6}{|c|}{ Syphilis test } \\
\hline & Yes & \multicolumn{3}{|l|}{ No } & \multicolumn{2}{|l|}{ Total } \\
\hline $\mathrm{P}^{0}$ & 62 & \multicolumn{3}{|l|}{27} & 89 & \multirow[t]{4}{*}{0.22} \\
\hline $\mathrm{P}^{1-4}$ & 157 & 43 & & & 200 & \\
\hline $\mathrm{P}^{5}$ and above & 25 & 9 & & & 34 & \\
\hline \multirow[t]{3}{*}{ Total } & 244 & 79 & & & 323 & \\
\hline & \multicolumn{6}{|c|}{ Blood group test } \\
\hline & Yes & \multicolumn{3}{|l|}{ No } & \multicolumn{2}{|l|}{ Total } \\
\hline $\mathrm{P}^{0}$ & 76 & 13 & & & 89 & 0.07 \\
\hline $\mathrm{P}^{1-4}$ & 152 & 48 & & & 200 & \\
\hline $\mathrm{P}^{5}$ and above & 23 & 11 & & & 34 & \\
\hline \multirow[t]{3}{*}{ Total } & 251 & 72 & & & 323 & \\
\hline & \multicolumn{6}{|c|}{ Tetanus toxoid vaccination } \\
\hline & None & One dose & Two dose & Three doses & total & P-value \\
\hline $\mathrm{P}^{0}$ & 25 & 2 & 61 & 1 & 89 & 0.07 \\
\hline $\mathrm{P}^{1-4}$ & 29 & 12 & 158 & 1 & 200 & \\
\hline $\mathrm{P}^{5}$ and above & 9 & 3 & 21 & 1 & 33 & \\
\hline \multirow[t]{3}{*}{ Total } & 63 & 17 & 240 & 3 & 321 & \\
\hline & \multicolumn{6}{|c|}{ Malaria prophylaxis prescription } \\
\hline & Yes & No & & & Total & P-value \\
\hline $\mathrm{P}^{0}$ & 19 & 70 & & & 89 & 0.70 \\
\hline $\mathrm{P}^{1-4}$ & 39 & 161 & & & 200 & \\
\hline $\mathrm{P}^{5}$ and above & 5 & 29 & & & 34 & \\
\hline Total & 63 & 260 & & & 323 & \\
\hline
\end{tabular}

Parity was not significantly associated with the components of antenatal care services 
Agu et al. Family Practice Reports 2015,

http://www.hoajonline.com/journals/pdf/2056-5690-2-2.pdf

doi: $10.7243 / 2056-5690-2-2$

Table 6. Cross tabulation between income and frequency of haemoglobin measurements, syphilis test, blood group test, tetanus vaccination and frequency of malaria prophylaxis prescription.

\begin{tabular}{|c|c|c|c|c|c|c|}
\hline \multirow[t]{2}{*}{ Income } & \multicolumn{6}{|c|}{ Frequency of haemoglobin assessment } \\
\hline & None & Once & Twice & Thrice & Total & P value \\
\hline No & 25 & 83 & 7 & 1 & 116 & 0.41 \\
\hline Yes & 33 & 165 & 8 & 1 & 207 & \\
\hline \multirow[t]{3}{*}{ Total } & 58 & 248 & 15 & 2 & 323 & \\
\hline & \multicolumn{6}{|c|}{ Syphilis test } \\
\hline & Yes & No & Total & & & P value \\
\hline No & 80 & 36 & 116 & & & 0.03 \\
\hline \multirow[t]{4}{*}{ Yes } & 164 & 43 & 207 & & & \\
\hline & 244 & 79 & 323 & & & \\
\hline & \multicolumn{6}{|c|}{ Blood group } \\
\hline & Yes & No & Total & & & P value \\
\hline No & 90 & 26 & 116 & & & 0.002 \\
\hline Yes & 161 & 46 & 207 & & & \\
\hline \multirow[t]{3}{*}{ Total } & 251 & 72 & 323 & & & \\
\hline & \multicolumn{6}{|c|}{ Tetanus toxoid vaccination } \\
\hline & None & Once & Twice & Thrice & Total & $P$ value \\
\hline No & 28 & 8 & 79 & 1 & 116 & 0.30 \\
\hline Yes & 35 & 9 & 161 & 2 & 207 & \\
\hline \multirow[t]{3}{*}{ Total } & 63 & 17 & 240 & 3 & 323 & \\
\hline & \multicolumn{6}{|c|}{ Malaria prophylaxis prescription } \\
\hline & Yes & No & Total & & & P value \\
\hline No & 28 & 88 & 116 & & & 0.12 \\
\hline Yes & 35 & 172 & 207 & & & \\
\hline Total & 63 & 260 & 323 & & & \\
\hline
\end{tabular}

Income was significantly associated with the syphilis test and the blood group test but not with the hemoglobin test, tetanus toxoid vaccination and malaria prophylaxis.

antenatal services is very important in achieving the objective of a good pregnancy outcome. This study audited the services that should be provided in antenatal care, which include recordings of Weight, Height, Blood Pressure (BP), screening for Anaemia, testing for Syphilis, Urine testing, Malaria prophylaxis, Tetanus toxoid immunization, HIV testing, and Micronutrient supplementation.

Though gain in maternal weight was more significance as a predictor of low birth weight, birth asphyxia and mode of delivery than maternal weight alone, most women do not know their pregravid weight therefore maternal weight was used as reference [14-16]. Measurement of maternal weight as an audit of the services provided was recorded in only $65.9 \%$ of the women. This recorded figure is low, compared to the recordings of maternal weight by Osungbade et al and Sagay et al., $97.3 \%$ and $78 \%$, respectively $[9,17]$. Maternal height, another important predictor (cephalopelvic disproportion) of pregnancy outcome was only assessed in $33.7 \%$ of the women [18]. This figure is lower than that recorded in rural South Africa where $92 \%$ had their heights recorded but higher than that in Jos, Nigeria where there was no recording of the height $[17,19]$.
The implication of this finding is that these women's risk for cephalo pelvic disproportion could not be adequately evaluated.

Haemoglobin concentration was tested only once in $76.8 \%$ of mothers in this study. Although, this figure is higher than $42.8 \%$ and $19.2 \%$ recorded by Osungbade and Osungbade, it is sub optimal $[9,17]$. The fact that it was only checked once in $76.7 \%$ and never checked at all in $17.9 \%$ of the women is quite disturbing. Health workers should put more effort to get the mothers have their hemoglobin levels checked regularly as to identify anaemic mothers early and institute prompt management. Maternal anaemia contributes to increased maternal and perinatal mortality and it is a risk factor for iron deficiency in the infant with adverse behavioral and cognitive development in the child $[\mathbf{2 5}, \mathbf{2 6}]$. It is also an independent risk factor for low birth weights and preterm delivery [20-22].

In this study, prescription for iron and folic acid supplementation was up to $82 \%$. This was similar to that of Osungbade of $80 \%$ [9]. It was much higher than the figures in another study by Osungbade of 36.4\% [23].

Blood pressure recordings in this study was found to be up to $99.7 \%$ This finding was similar to the finding in rural south Africa and higher than $95.1 \%$ recorded in some parts of Nigeria $[\mathbf{9}, \mathbf{1 9}]$. Hypertension, preeclampsia and eclampsia are leading causes of maternal mortality. Early detection through $\mathrm{BP}$ measurement can alert the care providers to take actions that can reduce mortality rates.

The findings show sub optimal syphilis screening $75.5 \%$, sub-optimal blood group (77.7\%) and almost optimal HIV screening (99.4\%). In a study in sub-Saharan Africa only $40 \%$ of women were screened for syphilis [24]. Blood group testing was lower than $84 \%$ in the South African Study [19]. Syphilis can cause still births, preterm, low birth weights and congenital malformations. Blood group testing is necessary to detect Rhesus negative mothers by care providers who may be able to provide optimal treatment to the neonate. HIV testing uptake was quite high. The uptake was higher than that in a South African study (76\%) [19]. HIV testing is the means of enrolling in PMTCT services. The women received counseling during which the benefits to the unborn baby were explained to the mother.

In this study, $80.4 \%$ of mothers had Tetanus toxoid immunization, while about $5.2 \%$ received only one dose before delivery. This figure is higher than $34.8 \%$ tetanus immunization ( 2 doses) recorded by Osungbade and $56 \%$ by Adeiga $[9,25]$. Tetanus toxoid immunization is an intervention to prevent neonatal tetanus. To be effective, at least two doses should be given four weeks apart and ending two weeks before delivery. Age group was significantly related to the number of tetanus toxoid vaccination. Those of the younger age group had the least percentage of being vaccinated twice before delivery. Greater efforts should be made to get $100 \%$ of our women to receive at least two doses of tetanus toxoid vaccination.

In this study, the use of intermittent preventive therapy for malaria prophylaxis prescription was (19.5\%) much lower 
Agu et al. Family Practice Reports 2015,

than the figure (72.1\%) recorded by Osungbade, higher than $6.4 \%$ in another study by Osungbade, $0 \%$ in Jos and $60 \%$ by the National population commission, respectively $[9,17,23,26]$. Malaria prophylaxis provision should be encouraged by all health workers as we live in an endemic area.

Malaria in pregnancy has a high prevalence in Nigeria [27]. It worsens anemia, causes low birth weights, intrauterine growth retardation, congenital malaria and preterm deliveries $[\mathbf{2 8 , 2 9 ]}$. Bivariate analysis between parity, income and components of health care services provided showed only income was significantly related with the syphilis test and blood group test. This may be attributed to the fact that these tests have a higher price tag than that of hemoglobin test. Age was not significantly related to the other components of care except the frequency of tetanus immunization. The blood pressure check, tetanus toxoid vaccination and HIV tests are free.

\section{Conclusion}

The study shows that a high proportion of pregnant women attended antenatal care clinics at least four times before delivery. The audit of provision and utilization of the services of antenatal care was found to be suboptimal. Some important service components such as maternal weight and heights, tetanus immunization and malaria prophylaxis were grossly underprovided and underutilized by these women.

\section{Limitations}

The information were extracted from secondary data with the potential challenges of using secondary data collected for other purpose in a survey. These may include observer, interviewer errors, etc. However, any effect on the data is minimal and would act on both positive and negative ways as to nullify such effects on the result of the study.

\section{Recommendation}

We recommend that health workers be trained and retrained to carry out health education provide adequate services and encourage women to utilize the services provided during antenatal care. Equipment for the provision of these services should be readily available at the canters. Women should be encouraged to book early by increasing their awareness to the benefits of such behavioral change and providing them with incentives such as free antenatal health care for all pregnant women.

\section{Competing interests}

The authors declare that they have no competing interests.

Authors' contributions

\begin{tabular}{|l|c|c|c|}
\hline Authors' contributions & UA & MCA & GAN \\
\hline Research concept and design & $\checkmark$ & $\checkmark$ & -- \\
\hline Collection and/or assembly of data & $\checkmark$ & $\checkmark$ & -- \\
\hline Data analysis and interpretation & $\checkmark$ & $\checkmark$ & $\checkmark$ \\
\hline Writing the article & $\checkmark$ & $\checkmark$ & $\checkmark$ \\
\hline Critical revision of the article & $\checkmark$ & -- & $\checkmark$ \\
\hline Final approval of article & $\checkmark$ & $\checkmark$ & $\checkmark$ \\
\hline
\end{tabular}

\section{Acknowledgement}

We acknowledge the contribution of the medical record staff of Comprehensive Health Centre, Umunya who assisted us in retrieving records for the studies.

\section{Publication history}

Editors: Radha Y. Aras, Yenepoya University, India.

Dean Smith, University of Michigan, USA.

Received: 08-Jun-2015 Final Revised: 19-Jul-2015

Accepted: 27-Jul-2015 Published: 04-Aug-2015

\section{References}

1. WHO. Trends in Maternal Mortality: 1990 to 2008. Estimates developed by WHO, UNICEF, UNFPA and the World Bank; 2010. World Health Organisation. I Website

2. UNFPA. Country Profile for Population and Reproductive Health Policy. Development and indicators. 2005. UNFPA. I Website

3. Wirth M, Sacks E, Delamonica E, Storeygard A, Minujin A and Balk D. "Delivering" on the MDGs?: equity and maternal health in Ghana, Ethiopia and Kenya. East Afr J Public Health. 2008; 5:133-41. | PubMed Abstract | PubMed Full Text

4. Chigbu B, Onwere $\mathrm{S}$, Kamanu $\mathrm{Cl}$, Aluka C, Okoro O and Adibe E. Pregnancy outcome in booked and unbooked mothers in South Eastern Nigeria. East Afr Med J. 2009; 86:267-71. | Article | PubMed

5. Titaley CR, Dibley MJ, Roberts $C L$ and Agho K. Combined iron/folic acid supplements and malaria prophylaxis reduce neonatal mortality in 19 sub-Saharan African countries. Am J Clin Nutr. 2010; 92:235-43. | Article I PubMed

6. Vaughan JP and Morrow RH. Manual of Epidemiology for District Health Management. WHO. Geneva 1989; 126-128. | Article

7. National Population Commision (Nigeria) and ICF international. Nigeria Demographic and Health Survey 2013. Abuja, Nigeria, 2014. I Pdf

8. Dairo MD and Owoyokun KE. Factors affecting the utilization of antenatal care services in Ibadan, Nigeria. Benin J Post graduate Med. 2010; 12:1-6. | Article

9. Osungbade KO, Shaahu VN and Uchendu OC. Clinical audit of antenatal service provision in Nigeria. Health Care Women Int. 2011; 32:441-52. I Article | PubMed

10. Federal Ministry of health. Maternal Health and Obsterics Fistula. Nigeria Demographic and health Survey. Abuja, Nigeria. 2008; 125-42.

11. Moneyor. Academic study in the UK context blog (internet). Social classes in Nigeria in Moneyor. 2012. I Website

12. Umoh AV, Umiyoho AK and Abasiattal AM et al. Gestational Age at first Antenatal Visit in Uyo, Nigeria. Ibom Medical Journal. 2006; 1:13-17. | Pdf

13. Idowu OA, Mafiana CF and Dapo S. Anaemia in pregnancy: a survey of pregnant women in Abeokuta, Nigeria. Afr Health Sci. 2005; 5:295-9. PubMed Abstract | PubMed Full Text

14. Siega-Riz AM, Viswanathan M, Moos MK, Deierlein A, Mumford S, Knaack J, Thieda P, Lux LJ and Lohr KN. A systematic review of outcomes of maternal weight gain according to the Institute of Medicine recommendations: birthweight, fetal growth, and postpartum weight retention. Am J Obstet Gynecol. 2009; 201:339 e1-14. | Article | PubMed

15. Costa BM, Paulinelli RR and Barbosa MA. Association between maternal and fetal weight gain: cohort study. Sao Paulo Med J. 2012; 130:242-7. I Article I PubMed.

16. Miletic T and Stoini E. Influence of maternal pregravid weight, height and body mass index on birth weight of male and female newborns. Coll Antropol. 2005; 29:263-6. | Article | PubMed

17. Sagay AS, Ekwenpu CC, Kabiru M, Daru PC and Aisien AO. Audit of antenatal services in primary health care centres in Jos, Nigeria. Trop J of Obstetrics and Gynaecol. 2005; 22:147-151. | Article

18. Toh-Adam R, Srisupundit K and Tongsong T. Short stature as an independent risk factor for cephalopelvic disproportion in a country of 
Agu et al. Family Practice Reports 2015,

http://www.hoajonline.com/journals/pdf/2056-5690-2-2.pdf

relatively small-sized mothers. Arch Gynecol Obstet. 2012; 285:1513-6. | Article | PubMed Abstract | PubMed Full Text

19. Hoque $M$, Hoque $E$ and Kader SB. Audit of antenatal care in a rural district of KZN, South Africa. SA Fam Pract. 2008; 50:66-66d. | Article

20. Patra S, Pasrija S, Trivedi SS and Puri M. Maternal and perinatal outcome in patients with severe anemia in pregnancy. Int J Gynaecol Obstet. 2005; 91:164-5. | Article | PubMed

21. Bukar M, Audu BM, Yahaya UR and Melah GS. Anaemia in pregnancy at booking in Gombe, North-eastern Nigeria. J Obstet Gynaecol. 2008; 28:775-8. | Article | PubMed

22. Levy A, Fraser D, Katz M, Mazor M and Sheiner E. Maternal anemia during pregnancy is an independent risk factor for low birthweight and preterm delivery. Eur J Obstet Gynecol Reprod Biol. 2005; 122:182-6. | Article | PubMed

23. Osungbade K, Oginni S and Olumide A. Content of antenatal care services in secondary health care facilities in Nigeria: implication for quality of maternal health care. Int J Qual Health Care. 2008; 20:346-51. | Article | PubMed

24. Kuznik A, Lamorde M, Nyabigambo $A$ and Manabe YC. Antenatal syphilis screening using point-of-care testing in Sub-Saharan African countries: a cost-effectiveness analysis. PLoS Med. 2013; 10:e1001545. | Article | PubMed Abstract | PubMed Full Text

25. Adeiga A, Omilabu S, Audu RA, Sanni F, Lakehinde GP and Balogun O et al. Tetanus Toxoid immunization coverage among mothers of children below one year of age in difficult-to-reach area of Lagos metropolis, Nigeria. Afr J of Clinical \& Experimental Microbiology. 2005; 6:227-231. I Article

26. National population commission (NPC) (Nigeria) and ORC Macro. Nigerian demographic and health survey 2003. Calverton, Maryland: (NPC) (Nigeria) and ORC Macro. 2014. | Article

27. Okpere EE, Enabudoso EJ and Osemnenkha AP. Malaria in pregnancy. Niger Med J. 2010; 51:109-13. | Article

28. Rogerson SJ, Hviid L, Duffy PE, Leke RF and Taylor DW. Malaria in pregnancy: pathogenesis and immunity. Lancet Infect Dis. 2007; 7:10517. | Article | PubMed

29. Brabin BJ, Romagosa C, Abdelgalil S, Menendez C, Verhoeff FH, McGready R, Fletcher KA, Owens S, D'Alessandro U, Nosten F, Fischer PR and Ordi J. The sick placenta-the role of malaria. Placenta. 2004; 25:359-78. | Article | PubMed

Citation:
Agu U, Agu MC and Nnaji GA. Utilisation of
antenatal services at comprehensive health center
umunya, anambra state: a retrospective study.
Fam Pract Rep. 2015; $2: 2$.
http://dx.doi.org/10.7243/2056-5690-2-2

